\title{
Parejas heterosexuales serodiscordantes en Chiapas, México. La influencia del género en la expresión de la agencia \\ Heterosexual HIV-Discordant Couples in Chiapas, Mexico. The Influence of Gender in Agency Expression
}

\author{
Francisco Chong-Villarreal \\ Centro Regional de Formación Docente e \\ Investigacion Educativa (CRESUR), México
}

\author{
Teresa Margarita Torres-López \\ Universidad de Guadalajara, México
}

\begin{abstract}
Resumen
Hombres y mujeres heterosexuales con Virus de Inmunodeficiencia Humana (VIH) enfrentan desafíos personales (e.g. miedo a contagiar a otros y al rechazo) y sociales (el rechazo real). Para una persona con VIH (PV), estos son obstáculos en el desarrollo de su vida, especialmente si al formar una pareja, la otra persona no tiene el virus. A partir del supuesto de que las personas no carecen de poder para enfrentar y, ocasionalmente, transformar estructuras sociales, se elaboró este trabajo con el objetivo de explorar y comparar las estrategias seguidas por dos hombres y dos mujeres con VIH, en la formación de pareja, con personas que no tenían reporte (pareja serodiscordante). Los resultados destacan diferencias en las estrategias. Las dos mujeres experimentaron su sexualidad con hombres sin VIH. Sin embargo, ocultaron su diagnóstico a los hombres correspondientes. Tuvieron más dificultades, que los dos hombres, en su afán por mantener una relación de pareja estable. Además, han estado expuestas a riesgos de embarazo no deseado y violencia por ocultar el diagnóstico. Los hombres recurrieron al enamoramiento, para sostener una relación, donde la pareja correspondiente conoció, por información que ellos mismos les proporcionaron, su diagnóstico. Los resultados destacan que hay una inequidad en la disponibilidad de esquemas y recursos, entre hombres y mujeres. Frente al desafío de formar pareja y vivir la sexualidad, después del diagnóstico, las inequidades se reflejan en más dificultades y riesgos en las mujeres.
\end{abstract}

Palabras clave: VIH/SIDA, género, estigma, agencia, pareja serodiscordante

Francisco Chong-Villarreal; Centro Regional de Formación Docente e Investigacion Educativa (CRESUR), México; Teresa Margarita Torres-López, Universidad de Guadalajara, México.

La correspondencia en relación con este artículo se dirige a Francisco Chong-Villarreal, dirección electrónica: chongpac@yahoo.com.mx 


\begin{abstract}
:
Heterosexual men and women with Human Immunodeficiency Virus (HIV) face personal challenges (e.g. fear of infecting others and rejection) and social ones (real rejection). For a person with HIV (VP), these are obstacles in the development of their life, especially if forming a couple, where the other person does not have the virus. Based on the assumption that people do not lack the power to confront and occasionally transform social structures, this study was carried out in order to explore and compare the strategies followed by two men and two women with HIV, in forming couples, with people who did not have it (HIV-discordant couple). The results highlight differences in strategies. Although the two women experienced their sexuality with men without HIV, to do so, they hid their diagnosis from their prospective partners. They had more difficulties than the two men, in their eagerness to maintain a stable couple relationship. In addition, they were exposed to risks of unwanted pregnancy and violence, for hiding the diagnosis. The men resorted to falling in love, to sustain a relationship, where the corresponding partner knew their diagnosis, from information that the men themselves gave them. The results highlight that there is inequity in the availability of schemes and resources, between men and women. Faced with the challenge of forming a couple and living their sexuality after the diagnosis, inequities are reflected in more difficulties and risks for women.
\end{abstract}

Keywords: HIV/AIDS, Gender, Stigma, Agency, HIV-Discordant Couples

La Organización Panamericana de la Salud (OPS, 2003) expone que para comprender el VIH y el Síndrome de Inmunodeficiencia Humana (SIDA) se conformó una construcción social que devino en un mecanismo de control a través de normas que han condicionado la marginación social de quienes se encuentran fuera de estas. A dicha construcción se le denominó estigma asociado al VIH y SIDA (Parker \& Aggleton, 2002; Sontag, 2016). Los preceptos integrados en dicha construcción ya formaban parte del orden social antes de la aparición del virus y han servido para apuntalar el dominio masculino y heterosexual. Así, el VIH y el SIDA son asociados a grupos sociales que ya estaban marginados (e.g. homosexuales, trabajadoras sexuales, pobres). Señala la OPS (2003) que el estigma asociado al VIH y SIDA se funda en la ignorancia y soslaya, además, realidades presentes en la epidemia, como la existencia de mujeres, amas de casa, quienes también fueron afectadas desde un inicio.

Gupta, Odgen y Warner (2011) anotaron, en relación con la situación de las mujeres y el VIH, que la desventaja social en la que se encuentran ha bloqueado sus alternativas de respuesta a la epidemia. Por lo anterior, la Organización de las Naciones Unidas mujeres (ONU Mujeres, 2015) señaló que para responder de forma efectiva al problema que representa el VIH en todos los países, era necesario promover acciones que disminuyeran las inequidades de género al buscar las maneras de fortalecer la posición social y económica de las mujeres.

La vulnerabilidad de las mujeres frente al padecimiento se refleja en los datos estadísticos relativos a la epidemia. El Programa Conjunto de las Naciones Unidas sobre el VIH/SIDA(ONUSIDA, 2017), por ejemplo, señala que, si bien en todo el planeta las mujeres representan el $47 \%$ de todos los casos, en algunas regiones como África oriental y meridional, esta cifra es del 59\%.

En México, según el Centro Nacional para la Prevención y el Control del VIH y SIDA (CENSIDA, 2015), el número de mujeres portadoras ha decrecido en los últimos años en términos absolutos. Sin 
embargo, el número de mujeres con VIH representa una cifra que se ha incrementado proporcionalmente. En el año 2000, por ejemplo, se tenía un cálculo de 47000 mujeres con VIH. Para el año 2014, esta cifra había bajado a 40000 casos. Pero, mientras la primera cifra representaba el $16 \%$ de todos los casos; la segunda, el $21 \%$.

La construcción del estigma asociada al VIH y SIDA refleja un orden social inequitativo. El concepto de violencia simbólica desarrollada por Bordieu (Comboni \& Juárez, 2013) constituye una herramienta conceptual para comprender este proceso inconsciente de aceptación e interiorización de dicho orden, al imponerse una visión del mundo que se cimenta en el poder y la dominación. El estigma asociado al VIH y SIDA valida a un grupo social y las prácticas sexuales que lo apuntalan, como son la heterosexualidad y la monogamia. Además, dicho estigma ha sido un obstáculo para la prevención y la atención a las personas afectadas por el virus.

En relación con la prevención, en una publicación de ONUSIDA (2017), se detalla la forma en cómo las personas, para evitar el rechazo, evitan acudir a centros de atención para el VIH. Cuando los trabajadores de salud, por ejemplo, adoptan actitudes discriminatorias hacia personas con alto riesgo de infección, es menos probable que, estas, accedan a sus servicios. Con respecto a la atención, hay estudios (Conde-Higuera, Pimental-Ramírez, \& Díaz-Ávila, 2016; Zafra-Tanaka \& Ticona-Chavez, 2016) que destacan la correlación entre un mayor estigma percibido y una menor adherencia al tratamiento.

El tratamiento contra VIH, también conocido como tratamiento antirretroviral (TAR), en los últimos años es más simple, porque se ha disminuido la cantidad de medicamento que se consume, en comparación a lo que sucedía al principio de su uso. Además, el TAR, ahora, es más efectivo en la disminución del número de virus en el semen, así como en los fluidos vaginales y rectales. Estos avances han permitido la vivencia de una sexualidad menos dependiente del condón. También, se ha hecho posible la procreación con menos riesgo de transmisión del virus, independientemente del estatus serológico de las personas (Canada`s Source for HIV and hepatitis C information [CATIE], 2018; Eveland, 2016). En parejas serodiscordantes, es decir, cuando uno de los miembros tiene el virus y el otro no, es posible tener prácticas sexuales sin protección y sin riesgo de contagio. Siempre y cuando la persona con VIH tenga una carga viral indetectable, es decir, que la cantidad de virus en el cuerpo sea tan baja que no puede medirse (Bavinton et al., 2018; Cohen et al., 2016).

A pesar de los avances en el TAR, tanto el estigma asociado al VIH y SIDA, como la vulnerabilidad de las mujeres frente a la epidemia subsisten por la inequidad de género. Estudios realizados con parejas serodiscordantes (Kendall, Castillo, Herrera, \& Campero 2015; Ngure et al., 2015; Pintye et al., 2015) señalan una mayor vulnerabilidad de las mujeres. Pintye y colabores (2015) indican que, cuando no hay acuerdo en la pareja en la decisión de ser padres, tiende a prevalecer la influencia del hombre. Además, la inequidad parece tener efectos aún más adversos para la salud de mujeres con VIH, cuando en la pareja existe violencia. Roberts y su equipo (2016) han observado que las mujeres, que se encuentran en situación de violencia, suelen tener una menor adherencia al tratamiento.

\section{Planteamiento del problema}

A partir del estigma asociado al VIH y SIDA como marco explicativo de la epidemia, ONUSIDA (2007) y la OPS (2003) formularon directrices para guiar la acción global. Señalaron que se estaba ante 
un problema complejo y de múltiples facetas, porque el estigma opera tanto en lo individual, como en lo familiar, comunitario e institucional. Por ello, se propuso la creación de un plan amplio que integrara reformas políticas, en los marcos constitucionales de cada país, para garantizar la atención basada en el respeto a los derechos humanos de las personas afectadas. También, plantearon la necesidad de crear programas educativos sustentados en esos mismos principios de respeto. Para ello, fue necesario elaborar manuales que sirvieran de guías para una educación sexual que considere la prevención y la ruptura de prejuicios relativos a prácticas sexuales no heterosexuales.

Al considerar el poder del estigma para bloquear respuestas efectivas a la epidemia, se cuenta con estudios que han evidenciado su presencia en el personal de salud que atiende a las personas con VIH (Bermúdez, Bran-Piedrahira, Palacios-Moya, \& Posada-Zapata, 2015; Guardia-Medrano, Lenis-Restrepo, Toro-Castaño, Marñin-Gallego, \& Higuita-Gutiérrez, 2016; Zafra-Tanaka \& Ticona-Chávez, 2016). Se encontraron temores irracionales, estereotipos y prejuicios en torno a las PV en el personal de salud.

Los gobiernos en el mundo, comprometidos para dar una respuesta integral a la epidemia, reconocen (ONUSIDA, 2017) que se deben contemplar acciones conducentes a superar situaciones de desigualdad, tales como las que genera la pobreza y la construcción de género. Sin embargo, algunos países no cuentan con recursos suficientes para ello. Así, en Guatemala, por ejemplo, se han conjugado recursos provenientes de agencias internacionales, involucrado al gobierno y la sociedad civil para diseñar su respuesta (Programa Conjunto de las Naciones Unidas sobre el VIH/SIDA [ONUSIDA]-Programa de Naciones Unidas para el Desarrollo [PNUD], 2011).

En México, el gobierno, al principio, dio una errática respuesta a la epidemia. Negó servicios y soslayó el abuso que se cometió hacia las personas afectadas (Centro de Investigación en Enfermedades Infecciosas [CIENI]- Instituto Nacional de Enfermedades Respiratorias [INER], 2011). Actualmente, existe el Centro Nacional para la Prevención y Control del VIH y el SIDA (CENSIDA) una instancia con financiamiento gubernamental, que busca integrar y crear sinergia entre servicios de salud y grupos de la sociedad civil a fin de atender a las personas con VIH (PV) y fomentar la educación que disminuya el estigma y genere la prevención.

En general, en el mundo se ha configurado una respuesta al VIH y SIDA conformada principalmente de dos ejes vinculados entre sí. En primer lugar, se han buscado transformaciones estructurales para garantizar la atención y fomentar la prevención. A la par, se ha considerado la sensibilización de toda la población para la prevención y el apoyo a personas y grupos especialmente afectados por el estigma y la epidemia. Con base en la capacidad de las personas y los grupos, ONUSIDA ha diseñado manuales dirigidos a las PV donde se suministra información y rutas para defender sus derechos (a la vida, a la salud y a la no discriminación) (ONUSIDA, 2007; OPS, 2003). Pese a esas acciones, persisten miedos irracionales hacia las PV. Las PV, a su vez, no han sido pasivas y, generalmente, han actuado a pesar del estigma al desarrollar estrategias como aquellas que llevan a cabo para formar pareja o vivir su sexualidad. Se parte, en este trabajo, de que sus acciones son producto de decisiones reflexionadas, que se configuran a partir de los recursos disponibles. Un enfoque que destaca esa capacidad reflexiva es la teoría de la estucturación (Emirbayer \& Mische, 1998; Sewell, 1992). 


\section{La acción de las PV: respuesta al estigma}

La propuesta de teóricos de la estructuración (Emirbayer \& Mische, 1998; Sewell, 1992) puede enriquecer la comprensión de la acción de las PV, frente a los efectos discriminatorios del estigma y a la importancia que representan los recursos para dicha acción, tales como son la información y las habilidades personales. Estos autores subrayan que las personas no están completamente carentes de poder y pueden, desde la acción que cotidianamente realizan, incorporar cambios e incluso transformar estructuras. Dos conceptos fundamentales de esta propuesta son estructura social y agencia (Sewell, 1992). Las estructuras sociales se componen de esquemas y recursos. Los esquemas son procedimientos para la acción que van desde aquellos muy informales como los que se siguen en la elaboración de una receta de cocina, hasta los procedimientos más formales como los establecidos en las leyes de un país. En relación con los recursos, los hay humanos como la fuerza física, la destreza, los conocimientos, etc., y recursos no humanos como los edificios, las máquinas, etc. Su uso ayuda a mejorar o mantener el poder (Sewell, 1992).

La agencia Emirbayer y Mische (1998) apuntan que

...es la acción temporalmente construida por actores, quienes se encuentran en diferentes medio ambientes estructurales - contextos donde actúan temporalmente. Éstos, a través del interjuego de hábito, imaginación y juicio reproducen y transforman estas estructuras en las interactivas respuestas que dan a los problemas que enfrentan en las cambiantes situaciones históricas (p. 970).

Emirbayer y Mische (1998) sostienen que los actores humanos no solamente repiten rutinas pasadas, sino también son inventores de nuevas posibilidades para pensar y actuar. Incluso, la acción habitual y rutinaria es agéntica, en tanto involucra atención y esfuerzo que requiere imaginación y juicio para ajustar los esquemas recibidos y adaptarlos para alcanzar deseos, metas o para evadir amenazas. Es decir, aún en la aparente rutina, la acción no es mecánicamente determinada, porque los actores tienen que moldearla al seleccionar un repertorio práctico de actividades. Estos repertorios requieren un cierto grado de maniobrabilidad para asegurar la apropiada respuesta a la situación. Además, las acciones que los sujetos realizan no son radicalmente voluntaristas, porque los proyectos personales son un proceso culturalmente incrustado, dialógico, negociado tomando en consideración las reacciones de su contexto social. De esa manera, las personas construyen imágenes sobre a dónde se dirigen, las formas en cómo pueden alcanzar su meta a partir de su presente. Tales imágenes pueden ser concebidas con varios grados de claridad y detalle con un mayor o menor alcance en el futuro.

Por su parte, Sewell (1992) considera que los seres humanos han nacido con una alta capacidad para la agencia (lenguaje o respiración). Señala que hay diferencias en la manera de ejercerla (diferencias ínter e intra grupales). Estas dependen, en gran medida, tanto del conocimiento que tienen los actores de los procedimientos para la acción, así como de sus recursos disponibles. Por tanto, dichos recursos suelen estar distribuidos de manera desigual.

En concordancia con la opinión de Sewell (1992), estudiosos del género (Bosch, Ferrer, Ferreiro, \& Navarro, 2013; Esteban \& Tabora, 2008) coinciden en plantear que las inequidades en la distribución de recursos, a partir de normas sociales, se establecen procedimientos para la acción diferentes para hombres y mujeres. Esteban y Tabora (2008) refieren que "vivimos una organización social que ubica de forma diferente, desigual y jerárquica a hombres y mujeres, influyendo decisivamente en la subjetividad 
de las personas" (p. 62). Esta subjetividad es la internalización, la actuación y la reproducción de un conjunto de valores y actitudes que contribuyen con la perpetuación de la desigualdad entre los sexos.

\section{Pareja serodiscordante y agencia}

De acuerdo con la propuesta de teóricos de la estructuración, los hombres y las mujeres con VIH se encuentran en medio de estructuras sociales que los proveen de esquemas y recursos para enfrentar temores y amenazas o cumplir deseos y metas. Sin embargo, la acción de las PV no está condicionada mecánicamente por estos esquemas y recursos. Ello resulta posible, porque las personas están inmersas en múltiples estructuras, cuyos componentes se pueden transponer para responder a las motivaciones o los temores personales. Así, la construcción de género puede conferir recursos (roles, poder, esquemas, etc.), que contribuyen a superar un esquema que se interprete de la construcción estigmatizada del VIH y SIDA, como puede ser la idea de que una PV no debe establecer compromisos sentimentales con otra persona que no lo tiene para tener relaciones sexuales (protegidas o no). Los componentes de la agencia de las PV, para formar pareja y vivir su sexualidad, se representan en la tabla 1.

Tabla 1

Componentes de la agencia de PV de este estudio

\begin{tabular}{ccc}
\hline $\begin{array}{c}\text { Estructura } \\
\text { (esquemas y recursos) }\end{array}$ & Agente (persona con VIH) & $\begin{array}{c}\text { Resultado de la acción } \\
\text { Respuesta agéntica }\end{array}$ \\
\hline $\begin{array}{c}\text { Prescripción médica } \\
\text { Rol de género }\end{array}$ & Reflexión y acción & Pareja serodiscordante \\
Estigma asociado al VIH & (Metas: formar pareja, ejercer & la sexualidad \\
Programas y manuales para VIH & la sexualidad) & Rechazo \\
$\begin{array}{c}\text { Posición en estructura económica, } \\
\text { género, etc. }\end{array}$ & & Violencia \\
\hline
\end{tabular}

Fuente: elaboración propia.

A partir de la existencia de PV (hombres y mujeres), que han formado o intentado formar parejas con personas que no tienen el virus, se llevó a cabo este trabajo. Con base en el supuesto de teóricos de la estructuración de que las personas no están carentes de poder y pueden, a través de la reflexión y la evaluación de los recursos disponibles en su contexto estructural, desarrollar acciones que contravienen algunos esquemas estructurales (como los que se derivan del estigma asociado al VIH y SIDA) con la finalidad de comprender cómo opera la construcción de género en dicho proceso. El objetivo es explorar y comparar las estrategias implementadas por dos hombres y dos mujeres heterosexuales con VIH, con parejas que no tenían reporte de VIH. 


\section{Método}

Según Martínez (2006), el estudio cualitativo hermenéutico-dialéctico se emplea cuando la acción o el comportamiento humano se presta a diferentes interpretaciones (pp.102-113). En el proceso de interpretar, el desarrollo del conocimiento parte de conocimiento previo. La interpretación se articula a través de un proceso dialéctico en el que el significado de las partes o componentes está determinado por el conocimiento previo del todo (Ranitzky citado en Martínez, 2006, p.113). Dicho conocimiento, a su vez, se va corrigiendo y profundizando según crece el conocimiento de los componentes.

La muestra se conformó de entrevistas realizadas a dos hombres y dos mujeres con VIH. Dichas entrevistas fueron las mismas que se realizaron para un estudio previo (en el que se entrevistaron en total siete mujeres y doce hombres con VIH).

Para ilustrar el procedimiento, considerando que el presente estudio se realizó a partir de entrevistas de otro previo, se incluyen dos subapartados. El subapartado a) datos del estudio previo describe la metodología del estudio de donde se tomaron las entrevistas y en b) datos del estudio actual, se explica el procedimiento metodológico seguido para el presente trabajo.

\section{a) Datos del estudio previo}

El objetivo fue conocer las estrategias que siguen las PV para enfrentar el estigma en la familia y cubrir sus necesidades materiales (alimentación y vivienda) (Chong-Villarreal, Fernández,Huicochea, Álvarez, \& Leyva, 2014). Se usó un guion de entrevista con preguntas abiertas. Además, se obtuvieron datos sociodemográficos e información sobre temas relacionadas con las emociones y las acciones antes y después de recibir el diagnóstico (e.g. ¿Cuáles razones le llevaron a realizarse la prueba? ¿Quiénes lo acompañaron? ¿Cuáles emociones y pensamientos vinieron a su mente al conocer su diagnóstico? ¿Qué respuesta hubo en su familia ante el diagnóstico?, entre otras).

Las entrevistas se realizaron de abril a agosto de 2010. Las edades de todos los entrevistados tenían un rango de los 21 a los 59 años (promedio de 35 años). Las entrevistas se realizaron en uno de los dos centros de atención dentro de la Jurisdicción Sanitaria VII, en Chiapas, México (los que son encargados de atender a personas con VIH). Se contó con el apoyo del médico internista y de dos psicólogos de dicho centro para convocar a participantes y realizar la preparación logística. El criterio de inclusión se basó en que las personas fueran mayores de edad, participaran voluntariamente, no tuvieran dificultades físicas para comunicarse y contaran con, al menos, un año de haber recibido el diagnóstico.

La persona entrevistadora participó también en el análisis y la elaboración del presente trabajo y tiene como antecedente la colaboración en asociaciones civiles relacionadas con salud sexual y reproductiva (VIH y SIDA, trabajo sexual, migración y violencia). Durante las entrevistas, surgieron temas que no se consideraron en un principio. Por lo tanto, se siguió la sugerencia de Martínez (2006) de dejar fluir la información emergente si se considera relevante. Lo anterior toma en cuenta que las investigaciones cualitativas, si bien pueden partir de un problema específico, más bien abordan áreas problemáticas con temas 
entrelazados que emergen una vez iniciada la investigación ${ }^{1}$. En ese sentido, el tema de parejas serodiscordante fue abordado por dos hombres y dos mujeres participantes.

\section{b) Datos del estudio actual}

En la selección de la muestra para este trabajo, se consideró al total de hombres y mujeres quienes reconocieron que, después de recibir el diagnóstico, conformaron parejas sin reporte de VIH (pareja serodiscordante) (ver tabla 2).

\section{Tabla 2}

Datos generales de los participantes

\begin{tabular}{lccccc}
\hline $\begin{array}{c}\text { Nombre } \\
\text { asignado }\end{array}$ & Edad (años) & $\begin{array}{c}\text { Tiempo de } \\
\text { diagnóstico } \\
\text { (años) }\end{array}$ & $\begin{array}{c}\text { Número } \\
\text { de hijos }\end{array}$ & $\begin{array}{c}\text { Estado civil (antes } \\
\text { de formar pareja } \\
\text { serodiscordante) }\end{array}$ & Escolaridad \\
\hline $\begin{array}{l}\text { Mujer A } \\
\text { Mujer B }\end{array}$ & 28 & 4 & 2 & Viuda & Tercero de preparatoria \\
& 26 & 6 & 2 & $\begin{array}{c}\text { Viuda y separada } \\
\text { (dos relaciones) }\end{array}$ & $\begin{array}{c}\text { Tercero de secundaria } \\
\text { Hombre A }\end{array}$ \\
Hombre B & 21 & 6 & 0 & Soltero & Tercero de secundaria \\
\hline
\end{tabular}

Fuente: elaboración propia.

El proceso de análisis, que destacó la formación de pareja serodiscordante, como fenómeno emergente, en tanto no se contempló en la descripción protocolar inicial, se asemeja a la propedéutica fenomenológica descrita por Martínez (2006, pp.263-290), donde para el análisis se requiere la disciplina mental que contiene la tolerancia para soportar la incertidumbre que trae salirse de lo familiar y observar nuevos fenómenos. Para ver este "nuevo" fenómeno, nos apoyamos de lecturas posteriores a la recolección de los datos, tales como las relacionadas con la perspectiva de género que, junto a la teoría de la estructuración, constituye el horizonte interpretativo de este fenómeno.

De la teoría de la estructuración, se adoptaron aquellas categorías que dan cuenta de la agencia de las PV (recursos, esquemas, reflexión, evaluación de recursos y acción); además, ante la consideración de la perspectiva de género, que existe un acceso inequitativo de esquemas y recursos, según el sexo de las personas. Se analizaron las categorías vinculadas a la teoría de la estructuración, por separado, según la persona entrevistada era hombre o mujer. De esa manera, se encontraron dos modelos o patrones de respuesta (masculino y femenino) ante el desafío de formar parejas serodiscordantes.

\footnotetext{
${ }^{1}$ Martinez (2006) sugiere: cuando se encuentra un tema más importante que aquel que se planteó al inicio, debe seguirse el "principio de Serendip", que consiste en dejar el primero por el segundo. En nuestro caso, se siguió con el objetivo planteado, pero no se bloquearon temas emergentes.
} 


\section{Nota para justificar un análisis con datos no recientes}

La antigüedad de los datos utilizados en este trabajo permitió una prolongada contrastación de los resultados. Esto es un recurso de triangulación, según establece Flick (2014). La contrastación se llevó a cabo con investigadores (especialistas en salud sexual y reproductiva, así como en temas de género) en foros académicos, como el realizado el 25 de junio de 2015, en el marco del Seminario Permanente de Estudios sobre Violencias, en el Centro de Estudios Superiores de México y Centroamérica (CESMECA) donde se presentó la ponencia "Respuesta creativa al estigma asociado al VIH y SIDA. La agencia de PV en el Soconusco Chiapas". En dicho evento, estuvieron, entre investigadores y estudiantes de posgrado, en la sala de exposición, un número aproximado de 25 personas. Así mismo, hubo un número similar que presenció el evento a través de videoconferencia. Además, por el vínculo de autores con asociaciones civiles, de manera informal, los resultados también se discutieron con colaboradores de las asociaciones Médicos sin Fronteras y Una Mano Amiga en la Lucha contra el SIDA. Por el interés generado en este proceso, se consideró pertinente este trabajo, porque abona a la comprensión de la agencia y a la discusión generada por las posibilidades que ofrece el TAR para una salud sexual y reproductiva y contra la prevención del virus.

\section{Consideraciones éticas}

El consentimiento informado fue grabado al inicio de cada entrevista. La propuesta de trabajo de campo fue presentada a miembros del comité de ética del Colegio de la Frontera Sur (México), a quienes se mantuvo al tanto del proceso.

\section{Resultados}

Para los resultados que aquí se presentan, las discusiones, referidas en el apartado de Método, operaron como mecanismo de presión para precisar y construir los componentes de la agencia, así como los límites y las posibilidades para la formación de pareja serodiscordante, según sea hombre o mujer.

Según relataron los dos hombres seleccionados, ellos adquirieron el virus estando solteros. En el caso de las mujeres fue en el contexto del matrimonio y las dos enviudaron por complicaciones del SIDA en sus parejas. Posterior a que reciben el diagnóstico y ya sin pareja, las cuatro personas participantes intentaron o formaron parejas con personas que no tenían un diagnóstico semejante al de ellas.

Antes del VIH, los hombres ejercen su sexualidad diferente a las mujeres, porque ellos tenían vida sexual con múltiples parejas. En cambio, ellas tendían a experimentar la sexualidad solo con la pareja. Para ilustrar estos comportamientos compartimos los siguientes testimonios. El primero es de un hombre de 27 años. El segundo corresponde a una mujer de 28.

(Antes del VIH, dice él,)...era más libre (porque andaba) con muchachas pues. Pues ahora ya no me ando enamorando de cualquier muchacha. Me da miedo decirles: "me pasa esto", que me rechacen o me digan algo... Porque eso de que infecto, (ellas) infectan a otros y así va corriendo el rollo...

Ella, por su parte, compartió que siempre estuvo dispuesta (sexualmente) para su esposo. 
... pues yo no anduve de loca... Porque siempre tengo en la mente eso de que yo estaba bien con él, en la casa. Cuando él estaba en la casa y me buscaba, ahí estaba yo. Siempre estaba yo, nunca le dije que no. Aunque a veces dice uno que, no quiere uno, pero siempre estaba con él. (Había) diferencias en la intimidad entre él y yo. Pero, siempre estaba con él.

Al enterarse de que tienen VIH, las PV experimentan las consecuencias sociales que lo acompañan, como son las exclusiones de ámbitos como en el campo laboral y el sexual. Ante ello, las PV recurren a su capacidad reflexiva y evalúan los recursos de que disponen para desarrollar estrategias que, en parte, cubran los deseos cancelados. Esta experiencia de las PV destaca su capacidad de agencia.

\section{Componentes de la agencia en la formación de pareja serodiscordante}

Las personas participantes, al momento de recibir el diagnóstico, lo hacen con la misma percepción estigmatizada que tiene la población de donde provienen. Se derivan de dicha percepción, esquemas (reglas o recomendaciones para la conducta) restrictivos para la vida sexual y de pareja. Los que incluyen, además del estigma asociado al VIH y SIDA, otros esquemas y recursos (mayor o menor acceso a poder, normas de comportamiento) incluidos en la construcción de género. Esto es, los hombres, pese a los nuevos obstáculos, mantendrán una relativa mayor independencia económica, así como mayor control en la dinámica de la pareja que las mujeres. Los esquemas y los recursos que derivan tanto del estigma asociado al VIH y SIDA, como los provienen de la construcción de género, apuntalan comportamientos contrastantes. Por una parte, aquellos que se derivan del estigma asociado al VIH y SIDA, tienden a la marginación de las personas afectadas. Las inequidades del género, por otra parte, proporcionan recursos y esquemas, donde los hombres tienen mayor dominio y control, que las mujeres, en la vida social y privada. Pese a las mayores restricciones de género, para las mujeres, ellas encuentran recursos para ejercer su sexualidad. Sin embargo, los resultados, las ponen en mayor riesgo que a los hombres, como a la violencia y a un embarazo no deseado.

Retomando la propuesta de teóricos de la estructuración, se puede ilustrar, en la tabla 3, los tres momentos para comprender la agencia que desarrollan las PV frente a la sexualidad y la formación de pareja.

Tabla 3

Agencia que desarrollan las PV frente a la sexualidad y la formación de pareja

\begin{tabular}{ccc}
\hline Estructura & Agente & $\begin{array}{c}\text { Resultado de la acción } \\
\text { Respuesta agéntica }\end{array}$ \\
\hline $\begin{array}{c}\text { Esquemas y recursos derivados } \\
\text { del estigma asociado al VIH y } \\
\text { SIDA. }\end{array}$ & Reflexión y acción & Modelo de pareja masculino \\
Esquemas y recursos derivados & $\begin{array}{c}\text { (Motivación: sexualidad y } \\
\text { pareja) }\end{array}$ & Modelo de pareja femenino \\
de la construcción de género. & & \\
\hline
\end{tabular}

Fuente: elaboración propia.

Las limitaciones para la vida sexual de las PV se alimentan del estigma en las propias PV (estigma interno), en la comunidad, así como en el personal de salud (estigma externo). En algún momento, mientras se realizaban las entrevistas, por ejemplo, se sostuvo una charla con una mujer que era personal 
de salud. Ella relató que, entre las dificultades en el servicio, estaba el no acatamiento, por parte de las $\mathrm{PV}$, de las recomendaciones trasmitidas en las consultas médicas y en los talleres informativos que se realizan para una vida sexual sin riesgo. Ella ejemplificó su aseveración diciendo que una paciente, que tenía varios años siendo atendida con TAR, se había embarazado recientemente.

En relación con el estigma en el campo laboral, uno de los hombres compartió que, al recibir el diagnóstico de VIH, fue dado de baja del ejército, institución en la que laboraba.

Se puede afirmar, en concordancia con teóricos de la estructuración, que las personas no llevan a cabo actos contrarios a las recomendaciones médicas, sin reflexión y sin evaluar las posibilidades que se les presentan. Más bien, son actos que, generalmente, se dan después de evaluar las alternativas disponibles.

En el análisis de los datos, se puede observar que se perfilan dos formas de proceder frente a la sexualidad y la formación de pareja dependiendo de si se es hombre o mujer. Los hombres parecen tener mayor éxito en la formación de pareja que las mujeres. En contraste, las mujeres llegan a experimentar una vida sexual, con hombres sin VIH, pero no conforman una pareja estable. A partir de aquí, se denomina al patrón formado por hombres como modelo masculino y al de mujeres, modelo femenino

En los siguientes dos apartados, se presenta, en primer lugar, el análisis que da cuenta del impacto del estigma, en la vida sexual y de pareja, como reflejo de los esquemas derivados del estigma asociado al VIH y SIDA. En segundo lugar, se presentan, en un solo apartado, los momentos que reflejan la tensión entre el deseo por experimentar la sexualidad o formar una pareja y la manera en cómo se va configurando tanto el modelo masculino como el femenino.

\section{a) El impacto del diagnóstico. Esquemas y recursos que bloquean una imagen de futuro como personas con pareja sexual}

Las PV, antes del diagnóstico, juegan roles distintos dependiendo de su sexo. Los hombres mantienen prácticas sexuales con múltiples parejas, mientras que las mujeres se reservan una vida sexual y social con el esposo. El diagnóstico a la prueba de VIH irrumpe en esa dinámica. Para mujeres que enviudan, con el diagnóstico se cancela no solo la seguridad económica, sino también la posibilidad de vida sexual posterior. Ante esa situación, las dos mujeres regresaron a vivir a la casa de sus padres. Ambas manifestaron desencanto y enojo. Una de ellas compartió lo siguiente: ... a veces digo yo, ¿por qué me tocó a mí? Pero yo sola. Yo no les digo a mis papás. Yo nada más. Cuando me lo digo yo, pue. Durmiendo y viendo la foto de él. Porque por él estoy así.

Para los hombres que aún no habían formado una pareja estable, al inicio, parecen percibir que, con el diagnóstico, se imposibilita dicha formación. Además, encuentran cerradas las posibilidades de conseguir trabajo; quedando como alternativa, para obtener recursos para la sobrevivencia material, participar en negocios familiares. El Hombre A, de 21 años, y quien recibió el diagnóstico a los 15, compartió los sentimientos de ese momento: ..., la verdad yo sufrí mucho. Lloré mucho, porque me dolió mucho, porque mi ilusión era ser militar.. Pensaba en mi enfermedad. Pensaba que nunca iba a tener una mujer... 


\section{b) Evaluación, reflexión y acción. Modelo masculino y femenino}

A pesar de las limitaciones imaginadas cuando se recibe el diagnóstico, los hombres y las mujeres participantes volvieron a experimentar la sexualidad con personas que no tenían VIH. En palabras de la teoría de la estructuración, se encontraron recursos disponibles para hacerlo.

Una comparación de los relatos (tabla 4) permite observar que el proceso de hombres y mujeres no es similar, porque disponen de recursos distintos y obtienen resultados diferentes.

\section{Tabla 4}

\section{Relatos de los participantes que evidencian los modelos masculino y femenino}

\section{HOMBRE A}

... Conocí a mi esposa... La hice mi novia... La conoci hace como cuatro años. Fuimos dos años de novios. (Fue dificil) decirle de mi enfermedad, porque me daba pena que un dia me fuera a rechazar. Porque yo estaba enfermo. Eso me ponía a pensar. La enamoré platicando y haciendo cariños. Duré un año para decirle que lo tenía.... Salió de mí. Porque la verdad la deseaba a ella y, como yo estaba enfermo, me daba miedo. Y ella apenas tenía 15 años... Se puso a llorar, muy triste. Pero, la verdad, nunca me dio la espalda.

\section{HOMBRE B}

Estuve como seis meses con ella (con su primera novia) de noviazgo. Pero, me daba miedo. (Después de los seis meses) Le dije: “¿sabes qué? Me pasa esto” (se refiere al VIH). Se agüitó. Empezó a llorar. Le empecé a platicar cómo estaba el show. Sí, nos juntamos...Ahorita estoy, parece, que por juntarme con otra chava. Igual ya sabe todo el rollo ya. Con ella, ya llevo ocho meses. (¿Cómo se lo dijiste?) No, pues igual...

\section{MUJER A}

Sostuvo por un tiempo una relación con intercambios sexuales para evitar el contagio. Ella recurría al argumento de que no deseaba embarazarse. Él le respondió: ...que yo tomara pastillas... (Yo le) decía que no me caían bien. Nunca me atrevía a decirle. Argumentó también que ella tenía miedo a enfermarse. En determinado momento, él le pidió que vivieran juntos y ella no aceptó. Finalmente, ante la insistencia de él de tener sexo sin condón, ella le dijo que tenía VIH. Pero, él no me creyó. Me dijo que no era cierto. Nada más era porque yo no quería estar con él. Que yo tenía a otro. Que no solo era él. Bueno, así me la fui llevando. Hasta que caí. Y ya acepté tener relaciones con él sin preservativo. Después, él se marchó y ella quedó embarazada por las prácticas sexuales sin protección en dicha relación.

... Al principio, yo me sentía mal porque acepté a tener relaciones sin preservativos... Le dije que no quería hacerle daño, porque a lo mejor se iba a encontrar otra mujer... Él me decía que no y que no... Yo le hablé. Yo le dije... De hecho, él antes de que se fuera, yo le volví a decir y no...

Continúa... 
Tabla 4

Relatos de los participantes que evidencian los modelos masculino y femenino

MUJER A

Comentó que no iba a tener ninguna otra relación. Sin pareja y si tengo, este, si me dan ganas (de tener sexo), nada más hacerlo, pero con cuidado (con condón).

MUJER B

... Quise empezar una relación bien bonita. Le digo (al hombre con quien quiere formar esa relación): “Sabes qué? Yo soy portadora”. Y salen huyendo. Ya me pasó tres veces. En esas experiencias, ella no ha dejado pasar mucho tiempo, una vez iniciado el cortejo, para compartir el diagnóstico. En la primera experiencia, dejó pasar aproximadamente un mes.

... Ando con una persona, pero no sabe que yo soy portadora ... Yo ando con él, pero con preservativo... Ya llevamos siete meses, creo, siete meses y medio... A veces, en mi alucín, digo: "Si se enamora de mí y con el paso de tiempo le digo y no sé si me vaya a cambiar (por otra mujer)". No sé. A veces, alucino yo solita. Luego, pienso: "No. Si se entera, a lo mejor hasta me asesine".

Para que él se ponga el condón, ella se lo pide al argumentar que no quiere tener hijos... Él a veces desconfía de mí. Dice que no es porque yo esté enferma, sino que... piensa que ando con más hombres y así.

Fuente: elaboración propia.

Las mujeres cuentan con pocas posibilidades para controlar la dinámica de una relación. En sus intentos por tener sexo protegido, los hombres (posibles parejas de las mujeres con VIH) presionan para mantener relaciones sexuales sin condón. Al principio, la mujer A utiliza como recurso, para convencer a su posible pareja, el argumento de que no desea embarazarse. Esta excusa la combina con la que corresponde a la intención de protegerse de alguna infección. De esa manera, procura sexo protegido. La insistencia de él, continúa. Ella, entonces, decide decirle que porta VIH. Él dice no creerle. Se complica, por ello, la posibilidad de practicar relaciones sexuales protegidas. Ante la presión de él, estas se dan sin protección y culmina con un embarazo no deseado.

La mujer B, en repetidas ocasiones y antes de tener relaciones sexuales, comparte su diagnóstico con diferentes hombres, quienes invariablemente se marchan después de la confesión.

La mujer A, quien fue abandonada por el padre de su bebé, dice que, después del parto, seguirá experimentando su sexualidad con condón. Si me dan ganas, nada más hacerlo, pero con cuidado. Es decir, ya no buscará formar pareja, pero tampoco compartirá el diagnóstico. La mujer B, por su parte, al momento de la entrevista, sostenía una relación de más de siete meses sin compartir el diagnóstico. En esos meses de relación, la mujer dijo que sus relaciones son protegidas. Usan como argumento la prevención de alguna infección. Ella manifestó temor a ser víctima de la violencia en caso de que el hombre se enterase de su diagnóstico. 
Los hombres, por el contrario, pueden experimentar la sexualidad con mujeres sin VIH. Ambos utilizan como recurso el enamoramiento. Ambos, a diferencia de las mujeres, pueden vivir la sexualidad mediante el empleo del condón. Sus parejas respectivas conocen el diagnóstico (ver tabla 5).

Tabla 5

Recursos de las PV para el ejercicio de una sexualidad con personas sin VIH

\begin{tabular}{ccc}
\hline Participantes & Recursos & Resultados \\
\hline Hombres con VIH & Enamoramiento & $\begin{array}{c}\text { Sexo protegido dentro de una pare- } \\
\text { ja formal. }\end{array}$ \\
Mujeres con VIH & Ocultamiento del diagnóstico. & $\begin{array}{c}\text { Sexo protegido en parejas no } \\
\text { formales. }\end{array}$ \\
& $\begin{array}{c}\text { Deseo de no embarazarse. } \\
\text { Prevención para una infección de } \\
\text { transmisión sexual. }\end{array}$ & $\begin{array}{c}\text { Posible violencia por ocultamiento. } \\
\text { Embarazo no deseado por sexo } \\
\text { desprotegido. }\end{array}$ \\
& $\begin{array}{c}\text { Posible criminalización por ocultar } \\
\text { el diagnóstico. }\end{array}$ \\
\hline
\end{tabular}

Fuente: elaboración propia.

El enamoramiento parece ser un recurso disponible para hombres con VIH, pero no así para el caso de las mujeres con VIH, para el ejercicio de una sexualidad con personas sin VIH. Al respecto, uno de ellos dijo: La enamoré platicando y haciendo cariños. Duré un año para decirle lo que tenía.

El enamoramiento parece que es un recurso de control que no es exclusivo de hombres con VIH. En un reportaje (Santiago, 2015) donde se entrevista a un hombre acusado de trata de mujeres, el reportero le pregunta ¿Cómo hizo para reclutar a un número de aproximadamente 200 mujeres en la trata? Él dijo: Una mujer enamorada hace todo por ti. Esta aseveración parece confirmarse en la entrevista (Vela, 2019) a una mujer que fue víctima. Ella describe cómo fue conducida:

Para ganarse la confianza..., (el tratante) le contó todo el sufrimiento que había pasado con su familia. Le dijo que desde niño fue maltratado, que dejó de estudiar para ayudar en su casa, que su padre golpeaba a su mamá. .... Una semana después, se volvieron a ver. Esa vez (él) le dio un oso de peluche y una caja de chocolates. Un regalo que (ella) nunca había recibido... Después de tres meses de muestras de amor, cariño y afecto, comenzó el horror (Vela, 2019). 


\section{Discusión}

De acuerdo con el análisis de los datos del presente estudio, el diagnóstico de VIH positivo afecta la vivencia de la sexualidad tanto a hombres y mujeres. El miedo a ser rechazados y de contagiar a otros son sentimientos compartidos por los participantes. Todo ello condiciona la manera de responder al deseo de formar parejas. Se analizó la experiencia de un grupo de hombres y mujeres con VIH, que establecieron parejas serodiscordantes desafiando las determinaciones del estigma asociado al VIH y SIDA (Pintve et al, 2015; Thomson et al., 2018), en su potencial para limitar tanto las posibilidades para formar parejas y de cómo llevar a cabo prácticas sexuales con personas sin VIH.

En el proceso de conformar pareja serodiscordante, se destacó que hombres y mujeres configuraron respuestas contrastantes. Se denominó, a la respuesta que llevaron a cabo los hombres para la formación de pareja, modelo masculino y a la que configuraron las mujeres, modelo femenino.

Las diferencias en los modelos para formar pareja o ejercer la sexualidad se centraron en la inequidad en el acceso a recursos y esquemas disponibles para tal objetivo. Ese inequitativo acceso a recursos y esquemas se reflejó en resultados diferentes. Las mujeres, además de tener menos posibilidades para formalizar una pareja, se ubicaron en situaciones de riesgo para un embarazo no deseado y de violencia por ocultar el diagnóstico.

En el modelo masculino hay, previo a la formación de pareja, una etapa de enamoramiento que concluye con la revelación del diagnóstico. Esto no cancela la posibilidad de intercambio sexual en dichas parejas. Existe el intercambio sexual, aun sabiendo ella, que él porta VIH. Este proceso que va del enamoramiento a la etapa cuando ya se tienen relaciones sexuales, no está exento del temor al rechazo. Parece que esa etapa previa de enamoramiento es fundamental para crear las condiciones emocionales para que la mujer, en cuestión, tenga menos posibilidades de abandonar la relación.

Con estos resultados, se destaca la importancia del acceso a más recursos y esquemas para que las PV lleven a cabo acciones que contengan un menor riesgo para su salud sexual y reproductiva. En ese sentido, hay propuestas (Gupta et al, 2011; Kendall et al., 2015; Saleem, Narasimham, Denison, \& Kennedy, 2017) que propugnan por la integración de la consideración del género en las estrategias de atención y prevención del VIH y SIDA. Dicha propuesta se puede enriquecer con recursos a manera de información como la relativa a las posibilidades que ofrece el TAR para el ejercicio de una sexualidad, menos dependiente del condón ( Bavinton et al., 2018; Cohen et al., 2016; Rodger et al., 2016), en las parejas serodiscordantes.

En relación con la integración de la perspectiva de género, Kendall y su equipo (2015) enfatizan la complejidad en la toma de decisiones en una pareja, por lo que en los procesos educativos -recomiendandebe contemplarse la intervención educativa para una sexualidad con menos riesgo, donde estén presentes ambos miembros de la pareja. Por su parte, Gupta y sus colegas (2011) agregan que se debe contribuir con mejores condiciones de poder, de las mujeres, tanto al interior de la pareja como en lo social. Lo anterior es importante para favorecer su posición en la toma decisiones que afectan su salud y la de su pareja.

En lo atinente a las posibilidades de una vida sexual menos dependiente del condón, hay trabajos (Bavinton et al., 2018; Cohen et al., 2016; Rodger et al., 2016) que reportan una disminución sustancial de riesgo de contagio al interior de la pareja serodiscordante. Lo anterior sucede cuando las PV tienen niveles indetectables del virus en la sangre, producto del consumo de TAR. Rodger y su equipo (2016) realizaron un estudio que se llevó a cabo en 75 clínicas de atención a PV, distribuidas en 14 países europeos, donde participaron 1166 parejas serodiscordantes. Las parejas seleccionadas debían tener, durante el periodo analizado 
(incluida en el estudio). El principal hallazgo fue que no se documentó algún caso de transmisión en las relaciones sexuales realizadas dentro de esas parejas.

Para una intervención preventiva que integre la transmisión de esa información a las parejas, Morton y colaboradores (2017) sugieren que sería recomendable la asesoría de un equipo multidisciplinario de atención y apoyo. Nguren y colabores (2016), por su parte, reportan un estudio que da cuenta de parejas a quienes se suministró información e insumos para la disminución de la carga viral en la pareja con VIH, así como recursos necesarios para la prevención (para quienes no lo tenían). Los resultados destacaron que las personas participantes sintieron que disponían de los recursos adicionales para la prevención. Además, fueron capaces de desarrollar estrategias para lograr la procreación cuando fue deseada. Los resultados de este estudio evidenciaron que esta estrategia confiere a las personas más confianza en sus prácticas sexuales y refuerzan la adherencia al tratamiento. Este estudio de Nguren y su equipo contrasta con lo que reportan Kendall y colegas (2015) en un estudio llevado a cabo con mujeres mexicanas, las cuales contaron con asesoría para el ejercicio de una sexualidad protegida. Ellas, las mujeres estudiadas, reportaron que las personas prestadoras de servicios de salud fueron insistentes en el uso del condón en todas las relaciones sexuales. Sin embargo, a pesar de que las mujeres dijeron estar convencidas de su uso, el estudio reportó que, durante sus prácticas sexuales, tuvieron un uso inconsistente. Se encontraron inequidades de género que incidieron en esos resultados, donde los hombres son quienes finalmente deciden su uso. Estas últimas aseveraciones resaltan que las estrategias de prevención, que se sostienen solamente en el uso del condón, no funcionan, porque las personas encontrarán fuertes motivaciones para no usarlo. Pintye y sus colegas (2015) reportan que una fuerte motivación es el deseo de procrear, bien sea para aprovechar que la PV, dentro de dicha relación, se encuentra aún en buen estado de salud o porque un bebé agregaría valor a la pareja. En esas condiciones, dicen los autores, cuando no hay acuerdo en el deseo de procrear, tiende a prevalecer la opinión de los hombres.

Los resultados apuntalan la necesidad de abrirse a nuevas estrategias donde las personas implicadas tengan más recursos en forma de información, como la relativa a las posibilidades que ofrece la adherencia al TAR, para la sexualidad. Se ha destacado que los recursos no operan mecánicamente. Las personas reflexionan y evalúan para actuar. Se requeriría, también, recurso en forma de apoyo; por ejemplo, un acompañamiento por un equipo de profesionales en la salud y en el comportamiento humano, así como discusiones en grupos multidisciplinarios para poder evaluar las ventajas y las desventajas de un proceso de esta naturaleza. Además, resultan indispensables estudios actualizados para elaborar propuestas probadas, donde las decisiones y las metas de las propias PV sean consideradas.

Limitaciones del presente trabajo. La obtención de los datos para este trabajo fue posible, en cierta medida, porque, quienes aquí participamos, hemos colaborado en asociaciones de apoyo a PV para enfrentar los efectos del estigma. Esa experiencia de colaboración probablemente contribuyó con la sensibilidad para realizar las entrevistas y obtener el apoyo logístico necesario. Sin embargo, se toma en cuenta que, ese proceso, se realizó en espacios de atención a PV. Para futuras investigaciones, sería recomendable, para aminorar sesgos de información, que se generen cuando se cuente con un centro de atención y efectuar la realización de entrevistas en otros espacios. De esa manera, los datos serán enriquecidos a través de la observación relativa a la dinámica que las PV establecen en su vida cotidiana, como la que llevan a cabo en el hogar o los lugares de esparcimiento. 
Nuevas investigaciones, sobre este fenómeno, son también necesarias, tomando en cuenta que la información, para este trabajo, se obtuvo hace más de ocho años. Las condiciones y las experiencias recientes podrían ofrecer resultados más novedosos que los hallazgos reportados. La antigüedad de los datos podría, de esa manera, estar comprometiendo la transferencia y la aplicabilidad de nuestra propuesta.

\section{Referencias}

Bavinton, B. R., Pinto, A. N., Phanuphak, N., Grinsztejn, B., Prestage, G. P., Zablotska-Manos, I. B. ... Grulich, A. E. (2018). Viral suppression and HIV transmission in serodiscordant male couples: an international, prospective, observational, cohort study. Lancet HIV, 5(8), PE438-E447. doi:10.1016/S2352-3018(18)30132-2

Bermúdez, V., Bran-Piedrahira, L., Palacios-Moya, L., \& Posada-Zapata, C. (2015). Influencia del estigma en torno al VIH en el acceso a los servicios de salud. Salud Pública de México, 57(3), 252-258. Recuperado de http:// www.scielo.org.mx/scielo.php?script=sci arttext\&pid=S0036-36342015000300014

Bosch, E., Ferrer, V.A., Ferreiro, V., \& Navarro, C. (2013). La violencia contra las mujeres. El amor como coartada. Barcelona: Anthropos Editorial.

Canada's source for HIV and hepatitis C information (CATIE) (2018). HIV treatment and an undetectable viral load to prevent HIV transmission. Fact sheet. Recuperado de https://www.catie.ca/sites/default/files/fsprev-viral-load-and-hiv-transmission-en-2018-09-10.pdf

Centro de Investigación en Enfermedades Infecciosas (CIENI) Instituto Nacional de Enfermedades Respiratorias (INER) (2011). 30 años del VIH y SIDA. Perspectivas desde México. Recuperado de http://www.censida. salud.gob.mx/descargas/biblioteca/documentos/30aniosdelvihsida.pdf

Centro Nacional para la Prevención y el Control del VIH y Sida (CENSIDA) (2015). Panorama de la respuesta nacional al VIH, México. Recuperado de http://www.gob.mx/cms/uploads/attachmentfile/31880/ Panorama nacional de la respuesta a la epidemia de VIH2015.pdf

Chong-Villarreal, F., Fernández, C., Huicochea, L., Álvarez, G.C., \& Leyva, R. (2014). Estrategias familiares de hombres y mujeres con VIH que buscan atender necesidades materiales en la región del Soconusco, Chiapas. Revista Liminar. Estudios Sociales y humanisticos, 12(1), 177-192. Recuperado de http://liminar. cesmeca.mx/index.php/r1/article/view/335/315

Cohen, M. S., Chen, Y. Q., McCauley, M., Gamble, T., Hosseinipour, M. C., Kumarasamy, N. ... Celentano, D. D. (2016). Antiretroviral Therapy for the Prevention of HIV-1. The New England Journal of Medicine, 375(9), 830-840. doi:10.1056/NEJMoa1600693

Comboni, S., \& Juárez J.M. (2013). Las interculturalidad-es, identidad-es y el diálogo de saberes. REencuentro. Análisis de Problemas Universitarios, 66, 10-23. Recuperado de http:// www.redalyc.org/pdf/340/34027019002.pdf

Conde-Higuera, P., Pimental-Ramírez, M., Díaz-Ávila,A., \& Domingo-Moratalla, T. (2016). Estigma, discriminación y adherencia al tratamiento en niños con VIH y SIDA: Una perspectiva bioética. Acta Bioeth, 22(2), 331340. Recuperado de https://scielo.conicyt.cl/scielo.php?script=sci abstract\&pid=S1726-569X2016000200 $\underline{020 \& \operatorname{lng}=\mathrm{es} \& \mathrm{nrm}=\mathrm{iso}}$ 
Emirbayer, M., \& Mische, A. (1998). What is agency? American Journal of Sociology, 103(4), 962-1023.

Esteban, M. L., \& Tabora, A. (2008). El amor romántico y la subordinación social de las mujeres: revisiones y propuestas. Anuario de psicología, 39(1), 59-73.

Eveland, J. (11 de enero de 2016). Start- and continue -HIV meds as soon as you can [Mensaje en un blog]. Recuperado de https://www.sfaf.org/collections/beta/start-and-continue-hiv-meds-as-soon-as-you-can/

Flick, U. (2014). La gestión de la calidad en investigación cualitativa. Madrid: Ediciones Morata.

Guardia-Medrano, A., Lenis-Restrepo, P., Toro-Castaño, D.C., Marín-Gallego, K., \& Higuita-Gutiérrez, L.F. (2015). Estigma y discriminación por VIH/Sida: perspectiva de los trabajadores del sector salud y un grupo de personas que vive con la infección; Medellín, Colombia, 2015. Curare, 2(1), 9-22. doi:10.16925/ cu.v2i1.1308

Gupta, G.R., Ogden, J., \& Warner, A. (2011). Moving forward on women's gender-related HIV vulnerability: The good news, the bad news and what to do about it. Global Public Health, 6(S3), S370-S382. Recuperado de https://www.tandfonline.com/doi/abs/10.1080/17441692.2011.617381

Kendall, T., Castillo, A., Herrera, C., \& Campero, L. (2015). El uso inconsistente del condón en mujeres mexicanas que viven con VIH: un reto para los servicios de salud. Salud Pública de México, 57(Supl. 2), S183-S189. Recuperado de http://www.scielo.org.mx/pdf/spm/v57s2/v57s2a12.pdf

Martínez, M. (2006). Ciencia y arte en la metodología cualitativa. Métodos hermenéuticos. Métodos fenomenológicos. Métodos etnográficos. Ciudad de México, México: Editorial Trillas.

Morton, J. F., Celum, C., Njoroge, J., Nakyanzi, A., Wakhungu, I., Tindimwebwa, E. ... Heffron, R. (2017). Counseling Framework for HIV-Serodiscordant Couples on the Integrated Use of Antiretroviral Therapy and Pre-exposure Prophylaxis for HIV Prevention. Journal of acquired immune deficiency syndromes, 74 (Suppl. 1), S15-S22. Recuperado de https://www.ncbi.nlm.nih.gov/pmc/articles/PMC5147040/

Ngure, K., Heffron, R., Curran, K., Vusha, S., Ngutu, M., Mugo, N., ... Baeten, J.M. (2016). I Knew I Would Be Safer. Experiences of Kenyan HIV Serodiscordant Couples Soon After Pre-Exposure Prophylaxis (PrEP) Initiation. AIDS patient care and STDs, 30(2), 78-83. Recuperado de https:// www.ncbi.nlm.nih.gov/pmc/articles/PMC4753630/

Organización de las Naciones Unidas para promover la igualdad de género y empoderamiento de las mujeres (ONU Mujeres). (2015). Hechos y cifras. El VIH y el sida. Recuperado de http://www.unwomen.org/ es/what-we-do/hiv-and-aids/facts-and-figures

Organización Panamericana para la Salud(OPS).(2003). Comprensión y respuesta del estigma y la discriminación por el VIH/SIDA en el sector salud. Recuperado de https://www.paho.org/hq/index.php? option=com content\&view=article \&id=230\%3A2008-understanding-responding-hiv-aids-related-stigma$\underline{\text { discrimination-health-sector\&catid }=1425 \% 3 \text { Apublications } \& \text { Itemid }=0 \& \text { lang }=\text { es }}$

Parker, R., \& Aggleton, P. (2002). Estigma y discriminación relacionados con el VIH/SIDA: Un marco conceptual e implicaciones para la acción. Documentos de Trabajo No. 9. Ciudad de México, México: El Colegio de México. 
Pintye, J., Ngure, K., Curran, K., Vusha, S., Mugo, N., Celum, C. ... Hefron, R. (2015). Fertility decisión-making among Kenyan HIV-serodiscordant couples who recently conceived: implications for safers conception planning. AIDS patient care STDs, 29(9), 510-516. doi:10.1089/apc.2015.0063

Programa Conjunto de las Naciones Unidas sobre el VIH/Sida (ONUSIDA) (2007). Reducir el estigma y la discriminación por el VIH: una parte fundamental de los programas nacionales del sida. Recuperado de http://data.unaids.org/pub/report/2009/jc1521_stigmatisation_es.pdf

Programa Conjunto de las Naciones Unidas sobre el VIH/Sida (ONUSIDA) (2017). Hoja informativa julio de 2017. Estadisticas mundiales sobre el VIH. Recuperado de http://www.unaids.org/sites/default/files/ media asset/UNAIDS FactSheet es.pdf

Programa Conjunto de las Naciones Unidas sobre el VIH/Sida (ONUSIDA)-Programa de Naciones Unidas para el Desarrollo (PNUD) (2011). Índice de estigma y discriminación en personas con VIH. Recuperado de http://www.stigmaindex.org/sites/default/files/reports/Guatemala\%20\%20People $\% 20$ Living $\% 20$ with $\% 20$ HIV\%20Stigma\%20Index\%20Report\%20\%20\%20Spanish\%20FINAL200512.pdf

Roberts, S. T., Haberer, J., Celum, C., Mugo, N., Ware, N. C., Cohen, C. R. ... Baeten, J. M. (2016). Intimate partner violence and adherence to HIV pre-exposure Prophylaxis (PrEP) in african women in HIV serodiscordant relationships: a prospectie cohort Study. Acquir Inmmune Defic Syndr, 73(3): 313-322. Recuperado de https://www.ncbi.nlm.nih.gov/pubmed/27243900

Rodger, A. J., Cambiano, V., Bruun, T., Vernazza, P., Collins, S., Lunzen, J. ... Lundgren, J. (2016). Sexual activity without condoms and risk of HIV transmission in serodifferent couples when the HIV-Positive partner is using suppressive antiretroviral therapy. JAMA. 316(2), 171-181. doi:10.1001/jama.2016.5148

Saleem, H.T., Narasimham, M., Denison, J.A., \& Kennedy, C.E. (2017). Achieving pregnancy safely for HIVserodiscordant couples: a social ecological approach. Journal of the International AIDS Society, 20(Suppl. 1), 18-23. doi:10.7448/IAS.20.2.21331

Santiago, A. (2015, 25 de octubre). Una mujer enamorada, hace todo por ti. Newsweek México. Recuperado de https://newsweekespanol.com/2015/10/una-mujer-enamorada-hace-todo-por-ti/

Sewell, W. (1992). A theory of Structure: Duality, Agency, and Transformation. American Journal of Sociology. 98(1), 1-29.

Sontag, S. (2016). La enfermedady sus metáforas. Elsidaysus metáforas. Editor digital Titivillus. Recuperado de http:// ceiphistorica.com/wp-content/uploads/2016/04/Susan-Sontag-La-enfermedad-y-sus-met\%C3\%A1 foras.-Elsida-y-sus-met $\% \mathrm{C} 3 \% \mathrm{~A} 1$ foras.pdf

The well project (2018). Depression, Women and HIV. The well project. Recuperado de https://www.thewellproject. org/hiv-information/depression-women-and-hiv

Thomson, K. A., Dhanireddy, Sh., Andrasik, M., Hancuch, K., Legg, L., Keane-Candib, J., \& Heffron, R. (2016). Fertility desires and preferences for safer conception strategies among people receiving care for HIV at a publicly-funded clinic in Seattle, WA. Clin. Infect Dis, 63(4), 548-554. doi:10.1093/cid/ciw335 
Vela, R. (2019). Siempre odié ese día porque llegaban más hombres: la explotación sexual aumenta el 14 de febrero. VICE noticias. Recuperado de https://www.vice.com/es latam/article/8xy55a/ siempre-odie-ese-dia-porque-llegaban-mas-hombres-la-explotacion-sexual-aumenta-el-14-de-febrero

Zafra-Tanaka, J.H., \& Ticona-Chávez, E. (2016). Estigma relacionado a VIH/SIDA asociado con adherencia al tratamiento, antirretroviral, en pacientes de un hospital de Lima, Perú 2014. Revista Peruana de Medicina Experimental y Salud Pública, 33(4), 625- 632. doi:10.17843/rpmesp.2016.334.2544

\section{Sobre el autor y la autora:}

Francisco Chong Villarreal es doctor en Ciencias en Ecología y Desarrollo Sustentable e investigador visitante del Centro Regional de Formación Docente e Investigación Educativa (CRESUR), México. Trabaja en temas de salud sexual y reproductiva, minorías por prácticas sexuales y migración. Se distingue como miembro del Sistema Nacional de Investigadores del Consejo de Ciencia y Tecnología (CONACyT) de México. Cuenta con más de diez publicaciones y ha participado como ponente en congresos nacionales e internacionales.

Teresa Margarita Torres López es doctora en Antropología Social y Cultural, profesora titular de la Universidad de Guadalajara, México y responsable de la línea de investigación "Procesos psicológicos y antropológicos sociales". Labora como docente en centros y universidades de diferentes países. Se destaca como miembro del Sistema Nacional de Investigadores del Consejo de Ciencia y Tecnología (CONACyT) de México y forma parte de la red de Investigadores Esculapio de COLCIENCIAS, Colombia. Cuenta con más de 100 publicaciones, comunicaciones y conferencias en congresos nacionales e internacionales. 